\title{
Belentung Sebagai Identitas Musik Pada Komunitas Konser Kampung Desa Jatitujuh Majalengka Jawa-Barat
}

\author{
Shintia Ananias ${ }^{1}$
}

\begin{abstract}
Belentung is a string instrument made by bamboo inspired by soundscape which is the voice of big toads and also children toys made by a can and thread of mattress. Belentung can be played individually or ansemble. The words "belentung" also refers to the ansemble or music that produced from belentung itself. Belentung ansamble music have four kinds of instrument based on their size and function, such as belentung panggede, panungtun, panembal and pangrecok.

Belentung made by Komunitas Konser Kampung located in the Jatitujuh village, Majalengka, West Java. Komunitas Konser Kampung has been established since June $26^{\text {th }}, 1987$ and have many art activities, such as in music activities, literature and fine arts. Members of this community are artists, humanists and youth generation of Jatitujuh. This community have so many art activities in Jatitujuh village itself and also in the level of region, Majalengka until out of region. The interaction of Komunitas Konser Kampung with other communities and also with the people made this community realized the importance of group identit, especially music identity. Belentung created as a music identity of Komunitas Konser Kampung because of the uniqness of the organology and the characteristic of their musical.

The qualitative method used to get data in the field, for example observation participate, interview with the local people, documentation and literature study. Ethnomusicology and anthropology approach has been done to analyze and made conclucion.
\end{abstract}

Keywords : Belentung, Identity, Komunitas Konser Kampung

\begin{abstract}
Abstrak
Belentung adalah alat musik gesek yang dibuat dari bambu yang terinspirasi oleh suara alam yang merupakan suara kodok besar dan juga mainan anak-anak yang dibuat dari kaleng dan benang kasur. Belentung bisa dimainkan secara individual atau ansemble. Kata-kata "belentung" juga mengacu pada ansemble atau musik yang dihasilkan dari belentung itu sendiri. Musik Belentung ansamble memiliki empat macam instrumen berdasarkan ukuran dan fungsinya, seperti belentung janggede, panungtun, panembal dan pangrecok.

Belentung dibuat oleh Komunitas Konser Kampung yang terletak di desa Jatitujuh, Majalengka, Jawa Barat. Komunitas Konser Kampung telah berdiri sejak 26 Juni 1987 dan memiliki banyak aktivitas seni, seperti dalam aktivitas musik,
\end{abstract}

\footnotetext{
${ }^{1}$ Mahasiswa Jurusan Etnomusikologi FSP Institut Seni Indonesia Yogyakarta
} 
sastra dan seni rupa. Anggota komunitas ini adalah seniman, aktivis dan generasi muda Jatitujuh. Komunitas ini memiliki begitu banyak aktivitas kesenian di desa Jatitujuh itu sendiri dan juga di tingkat daerah, Majalengka hingga ke luar daerah. Interaksi Komunitas Konser Kampung dengan komunitas lain dan juga dengan masyarakat membuat komunitas ini menyadari pentingnya identitas kelompok, terutama identitas musik. Belentung diciptakan sebagai identitas musik Komunitas Konser Kampung karena keunikan organologinya dan karakteristik musiknya.

Metode kualitatif digunakan untuk mendapatkan data di lapangan, misalnya observasi berpartisipasi, wawancara dengan penduduk setempat, dokumentasi dan studi pustaka. Etnomusikologi dan pendekatan antropologi telah dilakukan untuk menganalisis dan membuat kesimpulan.

Kata Kunci: Belentung, Identitas, Komunitas Konser Kampung

\section{Pendahuluan}

Komunitas memiliki empat sifat dasar, yaitu satuan yang kecil dari suatu unit, sifat homogen dari kegiatan dan pikiran anggotanya, berkemampuan memenuhi sendiri kebutuhan dan adanya kesadaran tentang perbedaan dengan kelompok atau komunitas lainnya (Irwan Abdullah, 2015 : 141-142). Salah satu sifat dasar dari sebuah komunitas yaitu, memiliki kesadaran tentang adanya perbedaan dengan kelompok atau komunitas lainnya membuat sebuah komunitas tidak akan terlepas dari kebutuhan akan sebuah identitas. Identitas memiliki arti ciri-ciri atau keadaan khusus seseorang, atau jati diri (KBBI). Pembentukan identitas suatu kelompok dapat melalui musik. Musik menjadi alat untuk mengkonstruksi identitas sebuah kelompok (Herniasih, Jurnal Kajian Seni, Vol. 01, No. 02 : 132).

Kebutuhan akan identitas dalam sebuah komunitas tidak hanya dapat dilihat dari sudut pandang kebutuhan dari komunitasnya saja, tapi juga dapat dilihat dari keberadaan komunitas itu sendiri di tengah masyarakat sekitarnya. Hal tersebut sama dengan sebuah komunitas seni yang berada di Desa Jatitujuh, Majalengka. Komunitas seni tersebut bernama Komunitas Konser Kampung. Komunitas ini merupakan sebuah komunitas yang bergerak dalam bidang seni dan beranggotakan masyarakat pelaku kesenian dan juga pencinta kesenian yang kebanyakan merupakan masyarakat Desa Jatitujuh, Kecamatan Jatitujuh, Kabupaten Majalengka, Jawa Barat. Letak Kabupaten Majalengka ini berbatasan langsung dengan wilayah Indramayu dan Cirebon yang memiliki budaya dan bahasa campuran antara Sunda dan Jawa. 
Budaya dan bahasa wilayah sekitar Majalengka mempengaruhi kesenian yang ada di Majalengka. Salah satu alasan Komunitas Konser Kampung membutuhkan identitas karena mereka memiliki anggota mayoritas termasuk dalam masyarakat Majalengka yang berada di antara budaya dan bahasa Sunda dan Jawa.

Belentung merupakan alat musik petik yang terbuat dari bambu dan dapat dimainkan sendiri atau secara bersama. Belentung juga merupakan sebutan untuk musik yang dihasilkan dari alat musik belentung sendiri. Alat musik belentung dibuat oleh Komunitas Konser Kampung. Belentung sendiri mengalami beberapa tahapan proses perubahan dari segi bentuk dan organologinya selama kurang lebih satu tahun. Belakangan, belentung disebut dan diakui sebagai identitas musik dari Komunitas Konser Kampung (Aminudin, wawancara, 4 November 2017).

\section{Komunitas Konser Kampung Desa Jatitujuih Majalengka Jawa-Barat}

Komunitas Konser Kampung merupakan sebuah kelompok pemuda Desa Jatitujuh dan sekitarnya yang memiliki minat yang sama yaitu pada bidang seni. Komunitas Konser Kampung berdiri sejak 26 Juni 1987 yang diprakarsai oleh seorang tokoh sastra Desa Jatitujuh bernama Uwa Kijoen dan juga seorang pemuda pada tahun 1987 bernama Didin Aminudin yang merupakan penikmat sekaligus pelaku kesenian khususnya musik (Uwa Kijoen, wawancara, 8 April 2018). Komunitas Konser Kampung banyak bergerak pada bidang seni sastra yang digerakkan oleh Uwa Kijoen dan bidang seni musik digerakkan oleh Didin Aminudin serta pada bidang seni rupa yang digerakkan oleh Subita. Beberapa kegiatan yang sering dilakukan oleh Komunitas Konser Kampung yaitu pertunjukan seni yang dapat berupa pagelaran seni musik dan sastra, pameran seni rupa, diskusi seni dan budaya, workshop, dan juga produksi kerajinan tangan dari bambu dan alat musik dari bambu.

Tahun 2011 terdapat sebuah festival musik di Cirebon yang meminta partisipasi dari Komunitas Konser Kampung untuk ikut memeriahkan festival tersebut. Pada saat itu, pihak festival musik meminta agar Komunitas Konser Kampung membuat sebuah alat musik yang berbeda dari alat musik yang sudah ada. Permintaan tersebut disanggupi oleh Komunitas Konser Kampung yang kemudian 
memunculkan ide untuk mengeksplorasi bunyi. Terinspirasi dari suara alam yaitu kodok besar dan juga alat permainan anak yang terbuat dari kaleng dengan benang yang ditarik-tarik, komunitas ini membuat sebuah alat musik yang kemudian diberi nama belentung. Pada saat itu belentung dimainkan sendiri dan dikolaborasikan dengan alat musik lainnya membawakan lagu sesuai yang diminta dari pihak penyelenggara festival musik tersebut. Belentung sendiri tidak serta merta memiliki bentuk seperti belentung pada saat ini (Subita, wawancara, 2 Mei 2018). Belentung mengalami beberapa proses perubahan dari segi organologinya. Ada empat tahap perubahan pada alat musik belentung sejak pertama belentung dibuat yaitu tahun 2011 hingga 2012. Mulanya, belentung terbuat dari tom-tom drum yang dipasangkan benang kasur kemudian dimainkan dengan menarik-narik benang tersebut. Kemudian karena kesulitan untuk memegang benang dan tom-tom drum yang berukuran cukup besar akhirnya ditambah dengan sebuah bambu panjang yang digunakan untuk merentangkan benang kasur tersebut. Kemudian munculah ide untuk menggantikan tom-tom drum dengan bambu dengan maksud agar bunyi yang dihasilkan lebih nyaring dan alat musik ini lebih mudah dibawa. Selain dibuat dari bambu, ada juga penambahan bambu yang digunakan untuk mengatur nada yang dihasilkan dari senar yang digunakan. Kemudian penambahan suatu alat pada alat musik belentung agar belentung dapat distem (tuning). Beberapa tahapan perubahan tersebut menghasilkan alat musik belentung yang sampai saat ini digunakan oleh Komunitas Konser Kampung.

\section{Belentung Sebagai Identitas Musik}

Belentung dapat diklasifikasikan ke dalam alat musik kordofon menurut sumber bunyinya yang berasal dari getaran senar atau dawai yang dipetik. Pengaturan nada pada alat musik belentung dilakukan dengan cara menekan dan mendorong bagian catang panekuk. Biasanya alat musik ini distem pada nada dasar E. Sesuai dengan pengukuran nada yang telah dilakukan pada 1 Mei 2018, alat musik akan menghasilkan nada-nada dengan rentang mulai dari $C$ sampai dengan $F$. Nadanada dihasilkan adalah $\mathrm{C}-\mathrm{C} \#-\mathrm{D}-\mathrm{D \#}-\mathrm{E}-\mathrm{F}$. 
Musik Belentung belum memiliki simbol-simbol dan cara penulisan notasi ke dalam sebuah partitur, untuk itu beberapa simbol yang digunakan merupakan simbol yang dipilih dan disesuaikan dengan frekuensi suara yang dihasilkan oleh belentung. Penentuan simbol tersebut terinspirasi dari notasi kendang pada Karawitan Sunda, Gamelan Degung. Penggunaan simbol digunakan dalam rangka mempermudah penulis dalam menganalisis pola ritme yang dimainkan dalam alat musik belentung dan diharapkan dapat mempermudah Komunitas Konser Kampung ketika harus melakukan pengajaran cara bermain alat musik belentung.

Belentung yang dimainkan secara ansambel terdiri dari beberapa alat musik belentung yang berbeda-beda ukuran dan memiliki nama masing-masing. Klasifikasi belentung menurut ukuran, fungsi dalam ansambel dan pola ritme permainannya:

\section{1) Belentung Panggede}

Belentung panggede merupakan jenis belentung yang paling besar daripada bentuk lainnya. Fungsi belentung panggede dalam ansambel belentung adalah sebagai pengganti bunyi bas karena bunyi yang dihasilkan belentung panggede merupakan frekuensi bunyi yang paling bawah atau rendah (low frequency).

Belentung panggede ini memang tidak terbuat dari bambu pada bagian awak. Hal tersebut dikarenakan kesulitan mencari bambu dengan diameter $40 \mathrm{~cm}$. Akhirnya dipilihlah pohon kelapa sebagai bahan dasar untuk bagian awak dengan permukaan dengan menggunakan membran dari mika. Belentung panggede memiliki catang dengan ukuran $1 \mathrm{~m}$ dan tidak memiliki catang panekuk karena pengaturan nada yang dihasilkan adalah dengan menekan senar atau dawai di setiap sisinya dari atas sampai ke bawah.

Pola ritme belentung panggede dalam setiap permainan musiknya adalah

Keterangan simbol bunyi pada notasi: $\mathrm{d}=d u n g$

a) Pola ritme pokok belentung panggede: $\mid \mathrm{d} \cdot \mathrm{dd} \cdot \mathrm{dd} \mathrm{dd}$

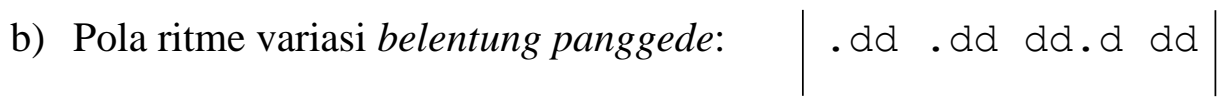




\section{2) Belentung Panungtun}

Belentung panungtun memiliki diameter awak yang cukup besar di dalam ansambelnya, yaitu dengan ukuran diameter awak $14,5 \mathrm{~cm}$, tinggi awak $37 \mathrm{~cm}$, panjang catang $56 \mathrm{~cm}$, dan panjang catang panekuk $22 \mathrm{~cm}$. Sesuai dengan namanya "panungtun", maka fungsinya dalam ansambel belentung adalah untuk menuntun permainan musik belentung lainnya agar ada kesesuaian tempo antara satu dengan lainnya serta menjaga agar bentuk lagu dan pola permainan saling berkesinambungan.

Belentung panungtun memiliki pola ritme yang lebih sederhana daripada belentung panggede. Belentung panungtun juga memiliki pola ritme yang pokok dan pola ritme variasi. Pola ritme pokok dimainkan sepanjang mengiringi lagu, sedangkan pola ritme variasi dimainkan pada akhir-akhir kalimat lagu dan terkadang mengikuti ritme syair dari lagunya sendiri.

Keterangan simbol bunyi pada notasi: $\mathrm{P}=$ pung

Pola ritme pokok belentung panungtun: $\mid \mathrm{P} \quad$. $\mathrm{P} \quad \mathrm{P} \mid$

\section{3) Belentung Panembal}

Belentung panembal ini biasanya merupakan belentung yang berukuran kecil dengan diameter antara $11 \mathrm{~cm}$, tinggi awak 26,5 cm, panjang catang $35 \mathrm{~cm}$ dan panjang catang panekuk $22 \mathrm{~cm}$. Biasanya terdapat dua sampai tiga belentung panembal dalam satu ansambel dan dimainkan dengan saling mengisi atau saling mengimbal.

Keterangan simbol bunyi pada notasi: $t=$ tung

a) Pola ritme belentung panembal $\mathrm{I}$ :

b) Pola ritme belentung panembal II:

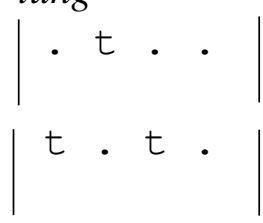

c) Pola ritme belentung panembal III:

$$
|\cdot t \cdot t \cdot t \cdot t|
$$




\section{4) Belentung Pangrecok}

Fungsi belentung pangrecok adalah untuk memberikan ornamentasiornamentasi atau variasi-variasi dalam ansambel ini. Pola permainannya lebih bebas daripada belentung yang lainnya. Belentung ini berukuran cukup besar dibandingkan yang lainnya, memiliki diameter $19 \mathrm{~cm}$, tinggi awak $90 \mathrm{~cm}$, panjang catang $1 \mathrm{~m}$ dan panjang catang panekuk $35 \mathrm{~cm}$. Salah satu contoh pola ritme yang dimainkan pada belentung pangrecok:

Keterangan simbol bunyi pada notasi: $\mathrm{b}=$ bung

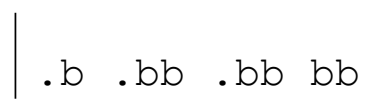

Pola ritme tersebut dibunyikan secara berulang-ulang selama mengiringi syair yang dinyanyikan, kemudian pemain belentung pangrecok diperbolehkan melakukan improvisasi pada saat interlude sedangkan pemain belentung lainnya tetap dengan pola ritme seperti pada saat mengiringi bagian vokal.

Pada intinya tidak ada pola ritme yang benar-benar pokok dalam permainan ansambel belentung. Pola ritme setiap alat musik belentung sangat dipengaruhi oleh kreatifitas dan ekspresi pemainnya pada saat mereka melakukan pertunjukan. Dengan kata lain, komunitas ini sangat mengutamakan improvisasi di atas panggung ketika mereka melakukan sebuah pertunjukan.

Salah satu lagu yang menjadi lagu andalan dan lagu yang dapat dikatakan sangat mencerminkan Komunitas Konser Kampung adalah sebuah lagu berjudul " $O y$ $O y O y$ ”. Lagu tersebut merupakan sebuah komposisi lagu yang khusus dimainkan dengan musik belentung. Lagu "Oy Oy Oy” diciptakan oleh Didin Aminudin, Ketua Komunitas Konser Kampung. Lagu ini menceritakan tentang alam dan kegiatan yang biasa dilakukan Komunitas Konser Kampung yaitu berkesenian dalam hal ini bermusik dengan menggunakan alat musik belentung. Lagu ini menggunakan tangga nada diatonic minor dan hanya menggunakan satu akor saja. Walaupun menggunakan tangga nada minor, bukan berarti lagu ini merupakan lagu bernuansa sedih melainkan sangat gembira.

Bentuk lagu "Oy $O y O y$ ” terdiri dari dua bagian yaitu bagian refrain yang dinyanyikan terlebih dahulu dan tiga bait. Ketiga bait tersebut mengandung unsur 
lirik yang puitis. Hal tersebut disebabkan karena komunitas ini memang sejak awal menekuni bidang sastra. Penggunaan lirik lagu dengan bahasa Indonesia menunjukan bahwa Komunitas Konser Kampung ingin agar setiap pendengarnya mengerti akan arti dari lirik lagu ini. Sedangkan kata " $O y$ " pada bagian refrain dapat dianalogikan seperti sedang memanggil para pendengar agar memberikan perhatian kepada komunitas ini kemudian pendengar diajak untuk mendengarkan cerita pada bait pertama. Setelah itu dinyanyikan kembali bagian refrain kemudian dilanjutkan ke bait yang kedua, demikians seterusnya hingga semua bait selesai dinyanyikan dan kemudian ditutup dengan dinyanyikannya bagian refrain. Berikut ini merupakan lirik lagu “Oy Oy $O y$ ” :

Refrain :

Bait I :

Oy.. Oy.. Oy.. Oy..

Di bawah sinar rembulan, daun-daun bergoyang

Dan embun menetes kembali, membasahi bumi

Bait II :

Kulantunkan nada, bunyi belentung mengiringi

Kelelawar mengukur malam, hingga malam berpulang

Bait III :

Nyanyikanlah lagu, sesuka hatimu

Berdendanglah, berdendang, hingga malam berpulang

Pada setiap pertunjukan yang dilakukan oleh Komunitas Konser Kampung, biasanya mereka menggunakan salah satu properti yang menjadi ciri khas dari masyarakat Sunda, yaitu ikat kepala atau biasa disebut dengan iket. Iket Sunda sebenarnya memiliki beberapa gaya, namun Komunitas Konser Kampung menggunakan iket dengan gaya makuta wangsa. Hal tersebut dilakukan dalam rangka menunjukan jati diri sebagai masyarakat Sunda ketika melakukan sebuah pertunjukan.

\section{Kesimpulan}

Komunitas Konser Kampung merupakan wadah atau tempat bagi masyarakat Desa Jatitujuh yang memiliki minat dalam bidang kesenian. Berbagai kegiatan kesenian telah menjadi daya tarik dari komunitas ini, baik dalam hal seni sastra, seni musik dan juga seni rupa. Selain kegiatan kesenian yang menyatukan setiap anggotanya, kekeluargaan juga menjadi salah satu kunci dari kebersamaan dan 
keberlansungan Komunitas Konser Kampung sejak tahun 1987. Komunitas Konser Kampung dapat dikatakan menjadi representasi dari seni dan budaya masyarakat Desa Jatitujuh karena keanggotaannya yang kebanyakan merupakan masyarakat Desa Jatitujuh sendiri.

Kebutuhan akan identitas musik menjadi semakin besar ketika Komunitas Konser Kampung bersinggungan dengan komunitas-komunitas kesenian lainnya di luar wilayah Jatitujuh. Identitas menjadi sebuah pembeda dan ciri yang khas dari komunitas agar komunitas tersebut memiliki daya tarik tersendiri bagi para penikmat seni. Musik belentung dipilih menjadi sebuah pembeda dan ciri yang khas dari Komunitas Konser Kampung. Alat musik dan juga musik belentung dibuat melalui ide dan gagasan dari anggota-anggota Komunitas Konser Kampung yang terinspirasi dari suatu hal yang sederhana, yaitu suara kodok besar yang biasa disebut dengan kata "belentung" dan juga sebuah mainan anak yang terbuat dari kaleng. Kesederhanaan yang terus disempurnakan selama kurang lebih satu tahun telah membuat alat musik belentung mengalami perubahan dari organologinya yang kemudian mempengaruhi bentuk alat musik ini secara visual. Organologi dan penyebutan bagian-bagian dari alat musik belentung berbeda dari alat musik pada umumnya, yaitu menggunakan bahasa sehari-hari masyarakat Desa Jatitujuh. Alat musik belentung kemudian digagaskan untuk dimainkan secara ansambel yang terdiri dari belentung panggede, panungtun, panembal dan pangrecok. Belentung memiliki pola ritme permainan dasar dan dapat dikembangkan menurut ekspresi dari pemain musik belentung. Komposisi musik yang dihasilkan dari permainan alat musik belentung ini menjadi representasi dari kearifan lokal masyarakat Desa Jatitujuh terlihat dari syair lagu "Oy Oy $O y$ ” yang menceritakan tentang kegiatan anggota Komunitas Konser Kampung, keadaan alamnya dan menceritakan tentang musik belentung sendiri. 


\section{Daftar Pustaka}

Abdullah, Irwan. 2015. Konstruksi dan Reproduksi Kebudayaan. Yogyakarta: Pustaka Pelajar.

Ekadjati, Edi S. 1984 Masyarakat Sunda dan Kebudayaannya. Jakarta: PT Girimukti Pasaka.

Hermiasih, Leilani. 2015. Diaspora Indonesia dan Gamelan Jawa di Inggris: Dampak Relokasi Tradisi Terhadap Pembentukan Identitas dan Komunitas. Queen's University Belfast: Jurnal Kajian Seni Vol. 01, No.02, 130-148.

Prier SJ, Karl Edmund. 2015. Ilmu Bentuk Musik. Yogyakarta: Pusat Musik Liturgi.

\section{Narasumber}

Didin Aminudin (49 tahun), Desa Jatitjuh, Kecamatan Jatitujuh, Majalengka,Pegawai Negeri Sipil Dinas Kesehatan Kabupaten Majalengka.

Subita (48 tahun), Desa Jatitjuh, Kecamatan Jatitujuh, Majalengka, Perupa, Divisi Seni Rupa Komunitas Konser Kampung

Uwa Kijoen (60 tahun), Kecamatan Kadipaten, Majalengka, Sastrawan, Pembina Komunitas Konser Kampung. 